\title{
What is a logic? Towards axiomatic emptiness
}

\author{
J.-Y. BÉZIAU ${ }^{1}$
}

\begin{abstract}
We first recall the original Greek sense of the word logic and how logic was developed on the one hand as an efficient way of reasoning by the use of reduction to the absurd and on the other hand as a useless system of logic by Aristotle. Then we discuss the changes of the modern conception of logic: the rejection of the principle of noncontradiction considered as fundamental by Aristotle and the structuralist move breaking the Aristotelian accident/essence dichotomy. Finally we explain why and how in universal logic - like in universal algebra axiomatic emptiness prevails: a logical structure is a structure obeying no axioms.
\end{abstract}

Keywords: universal logic, structure, axioms, principle of non contradiction

\section{In the beginning was the Logos}

"What is logic?" is a difficult question. In this paper we will tackle the issue through a simpler question "What is a logic?". We will explain why we can consider that a logic is a structure without axioms similarly to the case of universal algebra and giving the example of a simple logic, anti-classical logic, obeying none of the standard axioms that however can reasonably be considered as a logic. But it is important to keep in mind the more general issue of what logic is and to see how our answer to the simpler question is related and directed by this broader perspective.

Logic nowadays is generally the study of some logical systems related with mathematics, computer science, artificial intelligence or philosophy. These logical systems are sometimes called formal systems and their construction and study is developed using some

\footnotetext{
${ }^{1}$ Work supported by a grant DCR (Funcap/CNPq) and within the LogComp research project $(\mathrm{CNPq})$. Thanks to all members of Log Comp.
} 
mathematical tools at various degrees. Most of the time people have lost the more profound idea of what logic is.

It is good to remember that the word "logic" came from the Greek word "Logos", a key concept of Greek culture. The word "Logos" has four main interrelated meanings: reason, science, language, relation. Logic as an art of reasoning and logic as a logical system are not necessarily the same if we consider for example, like Descartes did, that we don't need a system to reason in a good way - Descartes was against syllogistic. Syllogistic is maybe the first system of logic, developed by Aristotle, who for that reason is often considered as the godfather of logic.

But before Aristotle, the emergence of the Logos in Greece manifested through a powerful way of reasoning: the reduction to the absurd. Using the strength of this reasoning the Pythagoreans were able to prove that the square root of 2 is not rational, a result which is considered sometimes as the first mathematical proof, hence the true birth of mathematics. The Pythagoreans had the idea that all reality is based on natural numbers and relations between natural numbers, so "rational" numbers were also admitted. A number that cannot be expressed as a relation between two natural numbers, an irrational number, was therefore something contradicting their views. But Logos was stronger than ideology and irrational numbers were admitted because they were born through reasoning, using the reduction to the absurd.

The reduction to the absurd, without being "formalized", became the main tool to develop mathematics. On the other hand Aristotle few decades later developed a system of logic, the syllogistic, where the reduction to the absurd does not appear explicitly and which was never used by mathematicians, or anyone, to produce interesting reasonings. But during 2000 years the study of logic was limited to syllogistic and someone like Kant even claimed that it was eternal. Aristotle is known to have characterized human beings as "rational animals", but the conception of rationality promoted by Aristotle is quite narrow, it is only one aspect of the Logos. We can say that in some sense Aristotle has blocked logic for 2000 years with his syllogistic and his metaphysical conceptions related to it: difference between accident and substance, subject and predicate, the claim that the principle of non-contradiction is the basis of rationality and 
reality. During the second half of the XIX century things started to change, this was the birth of modern logic.

\section{The modern conception of logic}

In modern times Aristotle's dogmas were rejected at two different levels: on the one hand the principle of non-contradiction was relativized and logics in which this principle does not hold were constructed (paraconsistent logics), on the other hand logical systems, including classical logic, were developed on a ground departing from Aristotle's metaphysics.

The Russian logician Vasiliev developed what he called imaginary logic or non-Aristotelian logic by analogy with the work of his colleague Lobatchevski also from Kazan. Vasiliev rejected the principle of non-contradiction and for this reason he is considered as a forerunner of paraconsistent logic. But Vasiliev was still working in the framework of Aristotelian thought, presenting variations of the syllogistic system.

The second forerunner of paraconsistent logic is the Polish logician Jan Lukasiewicz. In 1910 Lukasiewicz wrote a detailed criticism of Aristotle's arguments in favor of the principle of non-contradiction. At the end of this book there is a presentation of Schröder's idea of algebra of logic and this volume is considered as the book introducing modern logic in Poland. It is therefore the point of departure of the famous Polish school of logic which has been so fundamental in the development of modern logic. Lukasiewicz himself contributed very much to the development of modern logic working for example in many-valued logic.

But the real revolution of modern logic was not the contribution of one or two people; it was the rise of a new way of thinking which can be called "structuralism", which emerged in linguistics, mathematics, art and philosophy.

The idea of structuralism is that things are interrelated and that we can understand things through the relations they have. An object does not have an existence or meaning by itself. As well pointed out by Bourbaki, the number 4 does not exist by itself but only in relation with other numbers. This applies also to concrete objects like "particles" and to thought and language. For Saussure the meaning of a word does not only depend on its connection with reality 
but is delimited by the meaning of other words. The basic notion of structuralism is the notion of relation. This is really logical if we think of the original meaning of the word "logos".

Relations are described through the concept of structure - hence the name structuralism. We can say "to be is to be an object of a structure". To understand what an object is we have to appraise it in the appropriate structure. Different structures are possible and what also is important is to study the relations between structures, then we go at a higher level considering structures whose elements are themselves structures.

The theory of structures was developed in mathematics by Bourbaki, people working in universal algebra and category theory (Birkhoff / MacLane), and also by model theorists. Model theory, developed mainly by Alfred Tarski in the 1950s, was the final step of a long adventure in the development of modern logic and became the central subject of study in mathematical logic during three decades. Sometimes people use the word "semantics" to talk about model theory, but the word "semantics" was originally coined by Breal in a linguistic context. Model theory is much more than semantics in the linguistic sense; it is the full outcome of structuralism in logic. But there is also another aspect of this outcome taking place at a higher level of abstraction.

\section{Universal logic}

A logical system itself can be considered as a structure. There are different ways to define a logical system: via proof theory, via model theory or via some intermediate means such as tableaux. But a logical system can be considered as an abstract structure beyond syntax and semantics.

The first step in that direction is due to Tarski with his notion of consequence operator. This is a structure close to a topological structure - at this time (end of the 1920s) Tarski was working with Kuratowski. For this structure there are some axioms corresponding to reflexivity, monotonicty and transitivity of consequence.

The interesting point of Tarski's approach is that it is very abstract in the sense that consequence is not defined on a specific language, a specific set of formulas. A reason for this is that in the Polish school people were interested not only in mathematical reasoning 
but in general scientific reasoning, hence the expression they promoted for logic: Methodology of deductive sciences. Connectives do not appear at this level and therefore there are no laws such as the law of non-contradiction.

But Tarski's axioms for the notion of consequence can be criticized at two levels: concrete and abstract. At the concrete level one can find some counter-examples for such axioms, the most famous case are the penguins of non-monotonic logic. At the abstract level we may want to go even deeper in abstraction as this was done by Birkhoff in universal algebra.

Universal algebra - an expression coined by J.J. Sylvester was at first a general theory of algebras looking for some general laws or axioms for algebraic structures, such as associativity or commutativity. At the end of the XIXth century Whitehead wrote a big book on the subject: A treatise on universal algebra. But in the 1930s Garrett Birkhoff went deeper into abstraction by defining an abstract algebra just as a set with a family of functions on it no more axioms. His motivation was that the intersection of the two main groups of algebras (Noether /Boole) had no axioms in common, so unification could be done only in axiomatic emptiness. But Brikhoff showed that even at this level of axiomatic emptiness interesting work can be done: it is possible to define what a subalgebra is and also what morphisms are. These notions do not depend on any axioms, they are valid for all abstract algebras. We are at the level of concepts rather than axioms.

Axiomatic emptiness takes us back to a famous thought of Anaximander - considered as one of the first philosophical thoughts - "the undetermined (apeiron) is the principle (arche) of everything". This is quite different from Aristotle trying to base everything on the principle of contradiction.

For logic we can follow the same road to higher abstraction as in universal algebra and define a logical structure just as a consequence relation on a set. This is the idea of a logical structure in universal logic. It is important to emphasize that universal logic is therefore not the study of a universal system of logic from which everything can be deduced, a system which is the final explanation/description of the world or thought. It is in fact dubious that such system exists because on the one hand science is always evolving - new theories 
always appear, and on the other hand maybe the world and thought do not obey absolute laws, axioms or rules (contrarily to Kant's idea).

Universal logic is directly inspired by universal algebra but this does not mean that they are the same: both are keen of abstraction but they don't deal with the same kinds of structures: logical structures do not necessarily reduce to algebraic structures, they can be considered as a fourth type of basic mother structures in the sense of Bourbaki - by the side of algebraic, topological and order structures.

Such a jump into abstraction - performed in universal algebra and universal logic - allows space for monsters: we have limit structures close to nonsense and also very strange structures. In universal logic as limit structures we have a structure where everything is deducible from everything and its dual, nothing is deducible from nothing. And we have many strange structures which maybe don't describe any kind of natural or artificial reasonings. But this kind of jungle with a lot of weird animals is familiar to mathematicians. Limit structures are part of zeorology, the science of limit cases as named by Roland Fraïssé, and strange structures may one day turn to be in connection with reality as happened to nonEuclidean geometry. So the jump into abstraction makes sense from a methodological point of view and also for applications.

To end let us have a look at one of the monsters we have in the jungle of universal logic: anti-classical logic. This logic is just defined as the complement of classical logic: it is easy to check that it obeys none of Tarski's axioms. It also does not obey a further axiom which was put forward by Los and Suszko to improve Tarski's theory of consequence, the axiom of substitution. But why not considering anti-classical logic as a logic? It can be defined using recognized logical methods: proof methods (using for example the theory of refutation developed by Lukasiewicz) and semantics methods (using for example truth-tables).

\section{References}

[1] Bazhanov, V. Vasiliev : life and work // V.A.Smirnov (ed), Imaginary logic selected works. Nauka. Moscow. 1989.

[2] Béziau, J.-Y. Universal logic // Logica'94, P.Kolar et V.Svoboda (eds.), Académie des Sciences, Prague. 1994. P.73-93.

[3] Béziau, J.-Y. Recherches sur la logique universelle, $\mathrm{PhD}$ Thesis, Universite Denis Diderot (Paris 7). 1995. 
[4] Béziau, J.-Y. From paraconsistent logic to universal logic // Sorites. Vol. 12. 2001. P. 5-32.

[5] Béziau, J.-Y.(ed). Logica Universalis, Birkhäuser, Basel. 2005.

[6] Béziau, J.-Y. 13 questions about universal logic // Bulletin of the Section of Logic. Vol. 25. 2006. P.133-150.

[7] Béziau, J.-Y. Les axiomes de Tarski // R. Pouivet and M. Rebuschi (eds), La philosophie en Pologne 1918-1939, Vrin, Paris. 2006. P.135-149.

[8] Béziau, J.-Y. What is "formal logic"? // Revista Brasileira de Filosofia. Vol. 232. 2009. P.197-208.

[9] Béziau, J.-Y., Carnielli, W.A. et Gabbay, D.M. (eds) Handbook of Paraconsistency, King's College, Londres. 2007.

[10] Birkhoff, G. Universal algebra // Comptes Rendus du Premier Congrès Canadien de Mathématiques, Presses de l'Université de Toronto, Toronto. 1946. P.310-326.

[11] Birkhoff, G. Universal algebra // Rota, G.-C. and Oliveira J.S. (eds.), Selected Papers on Algebra and Topology by Garret Birkhoff, Birkhäuser, Bâle. 1987. P.111115.

[12] Boole, G. The mathematical analysis of logic, being an essay toward a calculus of deductive reasoning, Cambridge. 1847.

[13] Bourbaki, N. L'architecture des mathématiques // Les grands courants de la pensée mathématique, F. Le Lionnais (ed). 1948. P.35-48.

[14] Bréal, M. Essai de sémantique, Paris, 1897.

[15] Corry, L. Modern Algebra and the Rise of Mathematical Structures, Birkhäuser, Boston. 1996.

[16] De Morgan, A. Formal logic: or, the calculus of inference, necessary and probable, London. 1847.

[17] Dieudonné, J. Pour l'honneur de l'esprit humain, Hachette, Paris. 1987.

[18] Fraissé, $R$. La zérologie: une recherche aux frontières de la logique et de l'art: applications à la logique des relations de base vide // International Logic Review. Vol. 26. 1982. P.67-29.

[19] Glivenko, V. Théorie générale des structures, Hermann, Paris. 1938.

[20] Granger, G.G. Pensée formelle et science de l'homme, Aubier Montaigne, Paris. 1960.

[21] Granger, G.G. L'irrationnel, Odile Jacob. Paris. 1998.

[22] Hertz, P. Über Axiomensysteme für beliebige Satzsysteme // Matematische Annalen Vol. 101. 1929. P.457-514.

[23] Koslow, A. A structuralist theory of logic, Cambridge University Press, New-York. 1992.

[24] Eos, J. et Suszko, R. Remarks on sentential logics // Indigationes Mathematicae. Vol. 20. 1958. P.177-183.

[25] Lukasiewicz, J. On the principle of contradiction in Aristotle - A critical study, Krakow. 1910

[26] Lukasiewicz, J. et Tarski, A. Untersuchungen über den Aussagenkalkül // Comptes Rendus des séances de la Société des Sciences et des lettres de Varsovie XXIII, Classe III. 1930. P.30-50.

[27] Mossakowski, T., Goguen, J., Diaconescu, R. and Tarlecki, A. What is a Logic? // J.-Y. Béziau (ed). Logica Universalis, Birkhäuser, Basel. 2005.

[28] Porte, J. Recherches sur la théorie générale des systèmes formels et sur les systèmes connectifs, Gauthier-Villars, Paris et Nauwelaerts, Louvain. 1965.

[29] Rasiowa, H. et Sikorski, R. The mathematics of metamathematics, Académie Polonaise des Sciences, Varsovie. 1963.

[30] Riche, J. From universal algebra to universal logic // J.Y. Béziau and A. CostaLeite (eds). Perspectives on Universal Logic, Polimetrica, Monza. 2007. P.3-39. 
[31] Rougier, L. The relativity of logic // Philosophy and Phenomenological Research. Vol. 2. 1941. P.137-158.

[32] Rougier, L. Le traité de la connaissance, Gauthiers-Villars, Paris. 1955.

[33] Schanuel, S.H. et Lawvere, F.W. Conceptual mathematics - A first introduction to categories, CUP. 1997.

[34] Scholz, H. Abriss der Geschichte der Logik, Karl Alber, Fribourg. 1931.

[35] Sylvester, J.J. Lectures on the principles of universal algebra // American Journal of Mathematic. Vol. 6. 1884. P.270-286.

[36] Tarski, A. Remarques sur les notions fondamentales de la méthodologie des mathématiques // Annales de la Société Polonaise de Mathématique. 1928. P.270271.

[37] Tarski, A. Über einige fundamenten Begriffe der Metamathematik // Comptes Rendus des séances de la Société des Sciences et des lettres de Varsovie XXIII, Classe III. 1930. P.22-29.

[38] Tarski, A. Fundamentale Begriffe der Methodologie der deduktiven Wissenschaften. I // Monatshefte für Mathematik und Physik. Vol. 37. 1930. P.361-404.

[39] Whitehead, A.N.A treatise on universal logic, CUP. 1898.

[40] Wolenski, J. Logic and Philosophy in the Lvov-Wasaw School, Kluwer, Dordrecht. 1989. 